\title{
Determination of precise Galileo orbits using combined GNSS and SLR observations
}

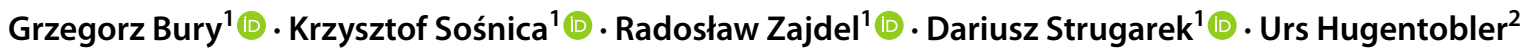

Received: 17 April 2020 / Accepted: 9 October 2020

(c) The Author(s) 2020

\begin{abstract}
Galileo satellites are equipped with laser retroreflector arrays for satellite laser ranging (SLR). In this study, we develop a methodology for the GNSS-SLR combination at the normal equation level with three different weighting strategies and evaluate the impact of laser observations on the determined Galileo orbits. We provide the optimum weighting scheme for precise orbit determination employing the co-location onboard Galileo. The combined GNSS-SLR solution diminishes the semimajor axis formal error by up to $62 \%$, as well as reduces the dependency between values of formal errors and the elevation of the Sun above the orbital plane- the $\beta$ angle. In the combined solution, the standard deviation of the SLR residuals decreases from 36.1 to $29.6 \mathrm{~mm}$ for Galileo-IOV satellites and $|\beta|>60^{\circ}$, when compared to GNSS-only solutions. Moreover, the bias of the Length-of-Day parameter is $20 \%$ lower for the combined solution when compared to the microwave one. As a result, the combination of GNSS and SLR observations provides promising results for future co-locations onboard the Galileo satellites for the orbit determination, realization of the terrestrial reference frames, and deriving geodetic parameters.
\end{abstract}

Keywords Galileo $\cdot$ GNSS $\cdot$ SLR $\cdot$ Precise orbit determination $\cdot$ Co-location

\section{Introduction}

Modern satellites of the global navigation satellite systems (GNSS) are commonly equipped with laser retroreflector arrays (LRA) for satellite laser ranging (SLR). As a result, two independent space techniques are co-located onboard navigation satellites. This allows investigating the orbital quality using SLR residuals as well as performing an independent GNSS orbit solution based solely on laser observations (Pavlis 1995). Moreover, GNSS orbits can be determined using the combination of two types of observations (Thaller et al. 2011; Hackel et al. 2015).

Electronic supplementary material The online version of this article (https://doi.org/10.1007/s10291-020-01045-3) contains supplementary material, which is available to authorized users.

Grzegorz Bury

grzegorz.bury@upwr.edu.pl

1 Institute of Geodesy and Geoinformatics, Wrocław University of Environmental and Life Sciences, Grunwaldzka 53, 50-357 Wrocław, Poland

2 Institute for Astronomical and Physical Geodesy, Technical University of Munich, 80333 Munich, Germany
The International Laser Ranging Service (ILRS, Pearlman et al. 2019) provides recommendations for the SLR stations in the form of the priority list of targets to be tracked. Nowadays, not only the dedicated geodetic satellites are tracked, but also plenty of other scientific missions including GNSS spacecraft. In 2013, the ILRS established a special study group, called Laser Ranging to GNSS s/c Experiment (LARGE) to organize special GNSS tracking campaigns. In 2018, two GNSS tracking campaigns were organized, between February 15 and May 15, and from August 1 to October 31 . The results of the second campaign are especially pronounced as eight Galileo satellites were recommended for tracking by the ILRS stations (see Fig. 1).

The research on the combination of microwave GNSS and SLR observations to GNSS satellites was mostly focused on the realization of the terrestrial reference frame (TRF) (Thaller et al. 2014, 2015; Glaser et al. 2015; Bruni et al. 2018). Urschl et al. (2007) assessed the formal errors of the GPS orbit semimajor axis based on sparse SLR data and simulated continuous SLR observations to GPS and GLONASS satellites. When the weights for the SLR and GNSS observations are the same, no improvement of the a priori formal error of the semimajor axis was achieved (Urschl et al. 2007). When the weight for SLR increases 


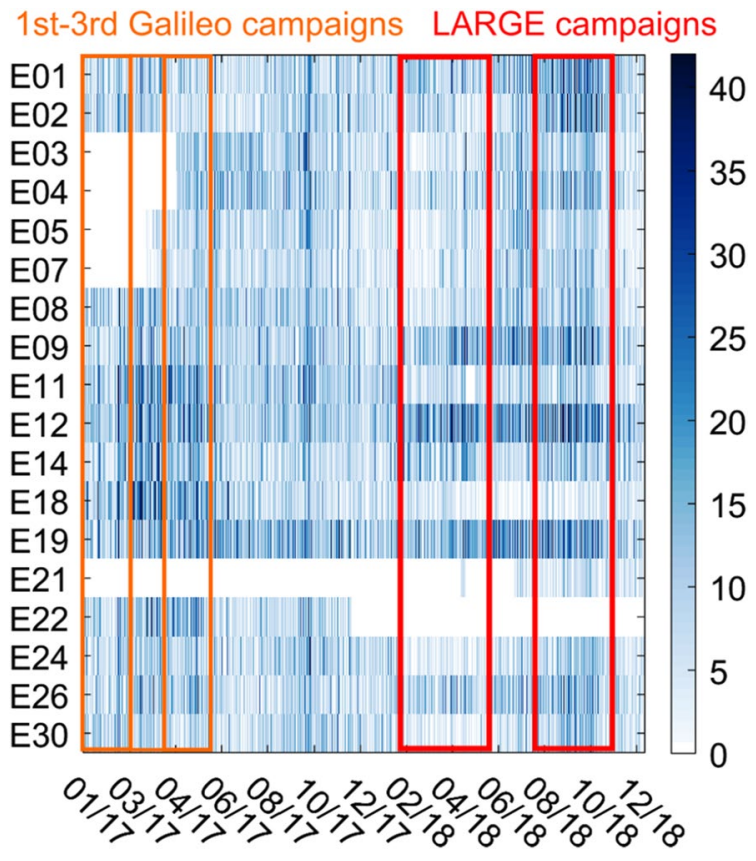

Fig. 1 Number of SLR observations to the Galileo satellites during 2017.0-2019.0 in 1-day intervals. Periods marked with orange and red frames indicate special tracking campaigns

by an order of magnitude, the formal error improves; however, the number of four SLR sites is insufficient to determine an accurate orbit solution.

Schönemann et al. (2007) and Hidalgo et al. (2008) incorporated SLR observations to determine the very first Galileo In-Orbit Validation Element (GIOVE-A and -B) orbits using combined SLR + GNSS solutions. In both studies, the combined solution was characterized by an improvement of the orbit overlap. However, in both cases, the number of GNSS stations tracking Galileo satellites was limited to 13 . In such a situation, any increase in the number of stations would be beneficial in terms of the improvement in the geometry of observations. As a result, the question arises, what would be the contribution of the SLR observations to the GNSS precise orbit determination (POD), if the GNSS data were provided by approximately 100 globally distributed stations, and the satellites were tracked by over a dozen of the SLR stations, as it is the case nowadays. Moreover, both studies applied higher, by an order of magnitude, weights for the SLR observations to GNSS satellites than for microwave GNSS observations. That is understandable because the orbit modeling issues were not resolved (Urschl et al. 2005), and the accuracy of early results for the GIOVE satellites was at the decimeter level (Steigenberger et al. 2011). Currently, the accuracy of GNSS and SLR techniques is significantly better, i.e., the a posteriori error of the multi-GNSS double-difference carrier phase solutions is at the level of $1.5 \mathrm{~mm}$ (Bury et al. 2020). Therefore, the weighting strategy should be reconsidered on that basis.

Hackel et al. (2015) conducted the Galileo In-Orbit Validation (IOV) orbit determination using combined GNSS and SLR observations. The internal consistency of the combined solution deteriorated in terms of, e.g., day boundary misclosures, compared to the GNSS-only solution. The solution consistency was improved by shifting the offset of SLR retroreflector by $5 \mathrm{~cm}$, which should rather be accounted for by the estimation of the SLR signature effect which depends on the laser incidence angle, and type of the LRA mounted on a satellite (Sośnica et al. 2018).

The goal of this study is to develop the best strategy for the precise Galileo orbit determination using combined GNSS and SLR-to-GNSS observations. We check the influence of SLR observations to GNSS satellites combined with microwave GNSS (GPS + GLONASS + Galileo) data collected by 100 GNSS stations and a dozen of SLR stations. We compare the combined solutions to microwave-based GNSS orbits whose accuracy is already at the centimeterlevel (Bury et al. 2020). We also test different weighting strategies to develop the optimal POD strategy using combined GNSS and SLR solutions.

\section{Methodology}

We conduct a series of Galileo POD test strategies to verify the impact of SLR observations on the combined SLRGNSS solutions for 2017.0-2019.0. As a reference solution, we determine purely microwave-based Galileo orbits $(M 1)$ based on ionospheric-free linear combinations of doubledifferenced GNSS phase observations collected by globally distributed stations, which follows the strategy described by Bury et al. (2019b) and Zajdel et al. (2019a, 2020). For the absorption of the direct solar radiation pressure (SRP), for all solutions, we use the hybrid approach based on the box-wing model for the Galileo satellites (Bury et al. 2020) and the empirical parameters consistent with the 5-parameter Empirical CODE Orbit Model (ECOM, Springer et al. 1999).

The 1-day normal equations (NEQs) for the microwave solutions are the basis for the combining SLR and GNSS solutions. The outliers in GNSS data are rejected in a preprocessing step. The GNSS-based NEQs are calculated using GPS, GLONASS, and Galileo observations provided by approximately 100 multi-GNSS stations distributed homogeneously worldwide. For SLR observations to GNSS satellites, NEQs are generated consistently with the strategy described by Bury et al. (2019a). Contrary to GNSS, the NEQs for SLR are not inverted at the preparation level due to their singularity, but instead, the observation residuals are rejected based on fixed orbits and station coordinates. We remove the SLR observations with residuals exceeding the 
threshold of $90 \mathrm{~mm}$. In contrast to the GNSS NEQs that are calculated using double-differenced phase observations, the SLR NEQs are calculated based on direct, absolute range measurements. The number of SLR observations is overwhelmingly lower as compared to GNSS, i.e., the median value of the GNSS observations for one day is about 882,809 for GNSS as compared to the 371 SLR observations for GLONASS and Galileo together. Eventually, the combination of the two types of observations demands to cope with different models dedicated to the particular technique. It is essential that both GNSS and SLR NEQs must be prepared using the same background models for orbit integration to avoid any sources of inconsistencies (see Table 1).

The combination of GNSS and SLR data is done at the NEQ level using the independent 1-day NEQs for GNSS and SLR with different weighting strategies. The a posteriori sigma of unit weight is at the level of $1.5 \mathrm{~mm}$ for the microwave Galileo solutions. For the SLR technique, the number of SLR observations to the Galileo satellites is insufficient to invert the SLR-only NEQ and obtain the a posteriori sigma. As a consequence, the accuracy of laser ranging to GNSS is established based on the SLR residuals to GNSS satellites using an online tool for the GNSS orbit validation with SLR (https://govus.pl/slr, Zajdel et al. 2017). For the best-performing stations, the standard deviation (STD) of the SLR residuals is at the level of $15 \mathrm{~mm}$; hence this value is assumed to be an indicator of the SLR data quality $(W 1)$. We also calculate the solution, for which the GNSS and SLR observations are treated equally (W3). Moreover, we provide an intermediate case with the mid-range weights for the SLR observations to test the effects of increasing the impact of SLR data (W2).

Table 1 List of models for GNSS and SLR data processing

\begin{tabular}{|c|c|c|}
\hline Component & GNSS & SLR \\
\hline Troposphere & $\begin{array}{l}\text { Dry part: Vienna Mapping Function (Böhm et al. 2006), wet } \\
\text { part: estimated }\end{array}$ & $\begin{array}{l}\text { Dry and wet based on meteorological data (Mendes } \\
\text { and Pavlis 2004) }\end{array}$ \\
\hline Ionosphere & $\begin{array}{l}\text { Ionospheric-free linear combination and modeling of the } \\
\text { higher-order terms and the bending effect (Hadas et al. } \\
\text { 2017) }\end{array}$ & - \\
\hline Reference frame & IGS14 (Rebischung et al. 2016) & SLRF2014 (Luceri et al. 2019) \\
\hline Sat. antenna model & $\begin{array}{l}\text { Phase center offsets (PCO) and phase center variations } \\
\text { (PCV) for GPS and GLONASS PCO for Galileo; based on } \\
\text { CODE MGEX ANTEX } \\
\text { (https://ftp.aiub.unibe.ch/CODE_MGEX } \\
\text { /CODE/M14.ATX) }\end{array}$ & - \\
\hline Rec. antenna model & $\begin{array}{l}\text { GPS, GLONASS: IGS14 } \\
\text { Galileo: Adopted from GPS L1 and L2 }\end{array}$ & - \\
\hline Observation sampling & $180 \mathrm{~s}$ & Normal points formed out of $300 \mathrm{~s}$ raw SLR data \\
\hline LRA offsets & - & Galileo metadata \\
\hline \multicolumn{3}{|c|}{ Common models in GNSS and SLR processing } \\
\hline Earth Gravity Model & EGM2008 (Pavlis et al. 2012) & \\
\hline Earth Orientation & A priori ERP: IERS-C04-14 (Bizouard et al. 2019) & \\
\hline Solid Earth tides & IERS2010 (Petit and Luzum 2010) & \\
\hline Ocean tides & FES2004 (Lyard et al. 2006) & \\
\hline $\begin{array}{l}\text { Ocean tidal loading and } \\
\text { geocenter corrections }\end{array}$ & FES2004, provided by Scherneck (1991) & \\
\hline Solid Earth pole tides & IERS2010 based on Desai (2002) & \\
\hline Mean Pole definition & IERS2010 (Petit and Luzum 2010) & \\
\hline Solar radiation pressure & \multicolumn{2}{|c|}{ A priori box-wing model based on the Galileo metadata (Bury et al. 2020) } \\
\hline $\begin{array}{l}\text { Albedo + infrared radia- } \\
\text { tion }\end{array}$ & \multicolumn{2}{|l|}{ CERES monthly maps (Wielicki et al. 1996) } \\
\hline Antenna thrust & \multicolumn{2}{|l|}{ IOV: 155 W, FOC: $200 \mathrm{~W}$ (Steigenberger et al. 2018) } \\
\hline Orbit integration & $\begin{array}{l}\text { Numerical integration based on least-squares collocation (Beu } \\
\text { Equation of motion: } \\
\text { Polynomial degree: } 10 \\
\text { Length of interval: } 5 \mathrm{~min} \\
\text { Variational equation: } \\
\text { Polynomial degree: } 12 \\
\text { Length of interval: } 6 \mathrm{~h}\end{array}$ & tler and Mervart 2010) \\
\hline
\end{tabular}


Table 2 A priori sigma and ratio values for GNSS and SLR observations

\begin{tabular}{lll}
\hline $\begin{array}{l}\text { Weighting } \\
\text { scheme }\end{array}$ & $\sigma_{\mathrm{GNSS}}[\mathrm{mm}]$ & $\frac{\sigma_{\mathrm{GNSS}}}{\sigma_{\mathrm{SLR}}}$ \\
\hline$W 1$ & 1.5 & $\frac{1}{10}$ \\
$W 2$ & 1.5 & $\frac{1}{4}$ \\
$W 3$ & 1.5 & $\frac{1}{1}$ \\
\hline
\end{tabular}

The weights for GNSS and SLR NEQs in this particular strategy is obtained using the $\sigma^{-2}$ values from Table 2 .

The datum is realized based on two sets of the GNSS and SLR stations. A priori GNSS station coordinates are expressed in the IGS14 reference frame, whereas the SLR site coordinates are referred to SLRF2014 all of which are consistent with the realization of the International Terrestrial Reference Frame (ITRF2014, Altamimi et al. 2016). Strugarek et al. (2019) proved that the differences between IGS14 and SLRF2014 are negligible and do not introduce any systematic effects to the combination of SLR and GNSS data onboard Sentinel-3A/B satellites. For the combined network of GNSS and SLR stations, we use minimum constraints, i.e., no-net-rotation (NNR) and nonet-translation (NNT) for both networks, as we simultaneously estimate the earth rotation parameters (ERPs) and geocenter coordinates (Table 3). For the GNSS technique, the minimum constraints are applied to the stations which were verified using residuals after Helmert transformation for each day of the solution (Zajdel et al. 2019a), whereas for the SLR, we use the ILRS core stations (https ://cddis.nasa.gov/lw21/docs/2018/splinter/ASC_CANBE RRA_2018_PRESENTATIONS.pdf). From the core station list, we rejected stations which may deteriorate the SLR solution because of station-specific systematics as recommended by Zajdel et al. (2019b). The ILRS core station list is prepared based on LAGEOS tracking, hence not all the core stations contribute to the GNSS tracking. In the best case, 13 SLR stations tracked Galileo satellites during the 1-day solution.

The NEQs, including two types of observations, i.e., the GNSS and SLR, are stacked to one NEQ for each day in program ADDNEQ2 of a modified version of the Bernese GNSS Software (Dach et al. 2015). The modifications of the Bernese GNSS Software include the extended handling of network constraining separately for SLR and GNSS stations, Galileo data processing using the a priori box-wing model based on Galileo metadata (GSA 2016), and optimized data processing and screening for SLR observations to GNSS (Bury et al. 2019a, 2020).

Apart from the station coordinates and the GNSS orbit parameters, which include six Kepler elements and five empirical parameters, we estimate the ERPs, the geocenter coordinates, troposphere zenith path delays, troposphere gradients, and SLR range biases (RBs). We calculate the annual mean RBs for each satellite-station pair (Appleby et al. 2016; Sośnica et al. 2019) which are then resubstituted as a priori values and strongly constrained in the processing. RBs treated in such a way do not deteriorate the orbit solution (Bury et al. 2019a).

\section{Results}

We check how the addition of the SLR observations influences the orbit geometry by analyzing the semimajor axis and its formal errors. The POD accuracy is assessed using the SLR residual analysis. We also analyze, how the SLR observations influence the satellite position, as well as the impact of SLR data on the empirical orbit parameters. Finally, we analyze

Table 3 Estimated parameters

\begin{tabular}{|c|c|c|}
\hline Parameter & GNSS & SLR \\
\hline Station coordinates & \multicolumn{2}{|c|}{$\mathrm{X}, \mathrm{Y}$, and Z for each GNSS and SLR station with NNR/NNT constraints for datum defining stations } \\
\hline $\begin{array}{l}\text { datum defining sta- } \\
\text { tions for NNR/NNT }\end{array}$ & $\begin{array}{l}\text { GNSS stations for which residuals of the Helmert transformation do not } \\
\text { exceed } 1 \mathrm{~cm} \text { for the horizontal and } 3 \mathrm{~cm} \text { for the vertical coordinates }\end{array}$ & $\begin{array}{l}\text { Set of the SLRF2014 core stations reduced } \\
\text { by stations showing systematic effects } \\
\text { McDonald (7080), Changchun (7237), } \\
\text { Wettzell (8834) }\end{array}$ \\
\hline Pole coordinates & \multicolumn{2}{|l|}{$\mathrm{X}$ pole and $\mathrm{Y}$ pole; two parameters per each component per day at midnigth epochs } \\
\hline UT1-UTC & \multicolumn{2}{|l|}{$\begin{array}{l}\text { Initial value fixed to the a priori from IERS-14-C04, } \\
\text { the drift of the UT1-UTC freely estimated (denoted as LoD) }\end{array}$} \\
\hline Geocenter coordinates & \multicolumn{2}{|l|}{$\mathrm{X}, \mathrm{Y}, \mathrm{Z}$ per each day } \\
\hline Orbital elements & \multicolumn{2}{|c|}{$\begin{array}{l}\text { GNSS orbit parameters: } 6 \text { Keplerian, } 5 \text { ECOM: } D_{0}, Y_{0}, B_{0}, B_{1 C}, B_{1 S}+\text { pseudo-stochastic orbit parameters in the radial, } \\
\text { along-track, and cross-track directions every } 12 \mathrm{~h}\end{array}$} \\
\hline Troposphere & Site-specific zenith total delay $(1 \mathrm{~h})$, gradients $(12 \mathrm{~h})$ & - \\
\hline Range Biases & - & $\begin{array}{l}\text { Annual range biases calculated for each } \\
\text { satellite-station pair; resubstituted and } \\
\text { strongly constrained to a priori in the } \\
\text { combined solution }\end{array}$ \\
\hline
\end{tabular}


the systematic drift of the accumulated Length-of-Day (LoD) parameter, also known as LoD bias (Senior et al. 2010), as it is correlated with the drift of the satellite ascending node and may serve as an additional orbit quality indicator. We also investigate RBs as a prerequisite for a reliable SLR solution and analyze the quality of the 2-day orbit predictions. The two later analyses are attached as supplementary material.

\section{Formal error of the semimajor axis}

The analysis of the semimajor axis formal error allows us to assess the impact of the addition of Galileo SLR observations on the solution precision. We check whether the small number of SLR observations, when added to the processing of GNSS observations, diminishes the formal error, and if so, we investigate whether there is any dependency between the number of the SLR observation and the reduction of the semimajor axis formal error for different strategies.

In all test cases, when we added SLR observations to the GNSS satellites, the formal errors of the semimajor axis are smaller as compared to the values from the microwave-only solution (Fig. 2). This is expected as the addition of a different type of observations to NEQs improves the observational geometry in the functional model. Even though the number of SLR observations is much lower than that for the GNSS technique, the impact of laser ranging is noticeable. SLR provides direct range measurements to the GNSS satellites, mostly in the radial direction. As a result, the SLR observations strengthen the solution thanks to their advantageous

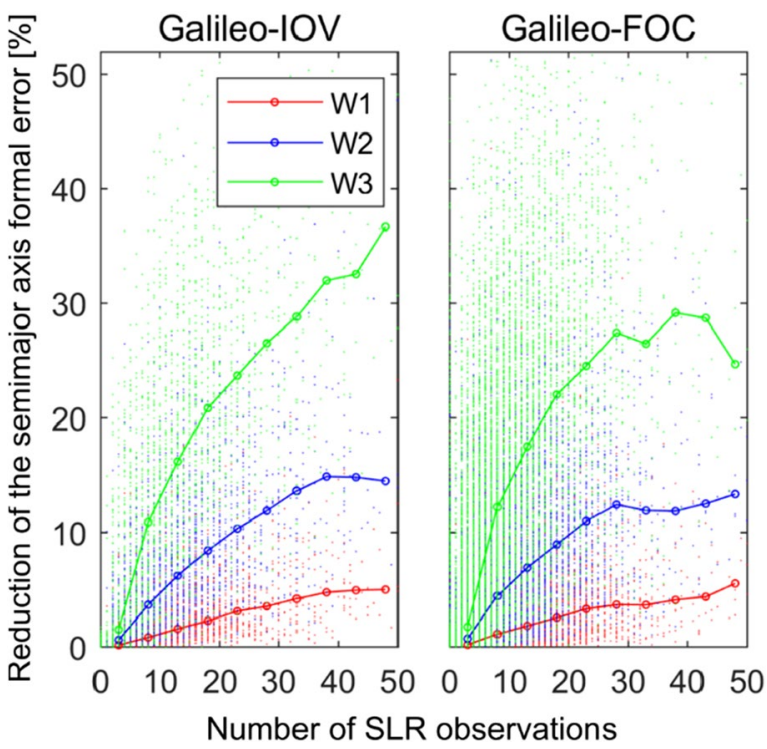

Fig. 2 Percentile reduction of formal error of the semimajor axis for the particular weighting strategies for Galileo-IOV (left) and GalileoFOC (right). Individual solutions are marked as faint dots, whereas median values (per bin of five SLR observations) are marked as large dots characteristic of direct range measurements, as well as improve the observation geometry.

The impact of the SLR technique increases with the number of observations contributing to the particular 1-day solution. Regardless of the strategy, the more SLR observations, the higher the reduction of the semimajor axis formal error. Moreover, the reduction increases when the SLR observations have greater weights. The addition of 50 SLR observations to the GNSS solution diminishes the mean error by 6 , 13 , and $25 \%$ for the Galileo-FOC, and 5, 15, and $37 \%$ for the Galileo-IOV for strategies $W 1, W 2$, and $W 3$, respectively.

The formal error of the semimajor axis also depends on the sun-satellite geometry. Figure 3 illustrates the reduction of the formal error of the semimajor axis as a function of the $\beta$ angle which is the elevation of the Sun above the orbital plane. We chose here the Galileo satellites from plane $\mathrm{C}$ that is characterized by the highest maximum $\beta$, i.e., $78^{\circ}$. The formal errors depend on $\beta$ in the microwave solutions in such a way that the largest errors are for maximum values of $|\beta|$ and for $|\beta|$ close to zero. When introducing SLR observations to GNSS satellites, the $\beta$-angle dependence diminishes for both IOV and FOC satellites. The mean formal error of the semimajor axis diminishes by 5,12 , and $23 \%$ for $W 1, W 2$, and $W 3$ solutions, respectively, for $|\beta|=78^{\circ}$.

\section{Analysis of the orbit misclosures}

Orbit misclosures evaluate the consistency level between the orbital arcs of consecutive days. The differences between
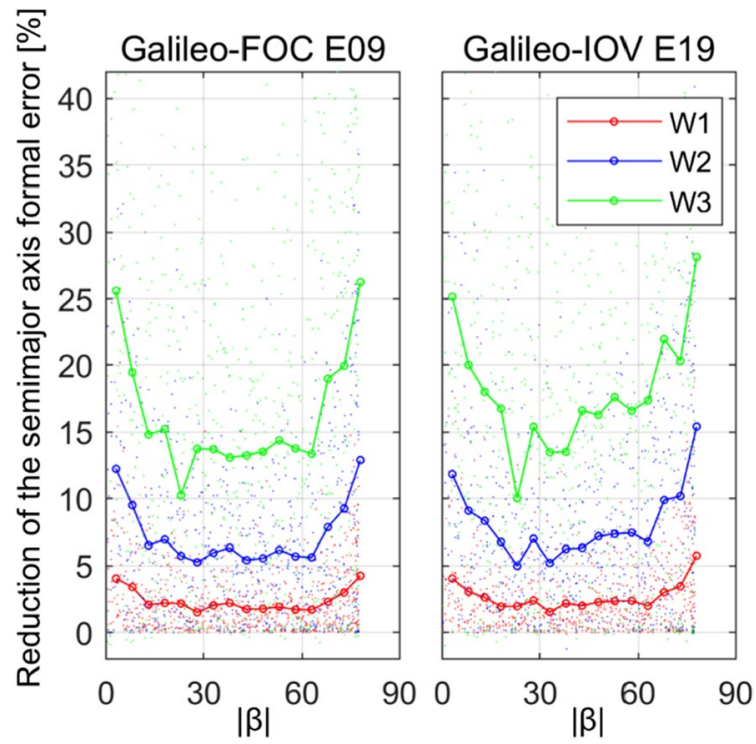

Fig. 3 Percentile reduction of the formal errors of the semimajor axis as a function of the $|\beta|$ angle for solutions $W 1, W 2$, and $W 3$ for the Galileo-IOV E19 (right) and Galileo-FOC E09 (left). Individual solutions are marked as faint dots, whereas median values (per bin of five degrees) are marked as large dots 
the satellite positions are calculated for the weakest determined part of the arc. The orbit misclosures are derived in the earth-fixed frame to obtain an impact of the SLR observations only on the orbital parameters and to exclude errors emerging from the calculated ERPs (Lutz et al. 2016). Figure 4 illustrates the orbit misclosures for the GNSS-based $M 1$ and combined solution calculated in test $W 1$, whereas Table 4 shows the orbit misclosure statistics for all strategies.

Contrary to the analysis of the semimajor axis formal error, the orbit misclosures are smallest for the SLR observation weights from solution $W 1$. For the radial direction, which is measured directly by the SLR technique, the mean
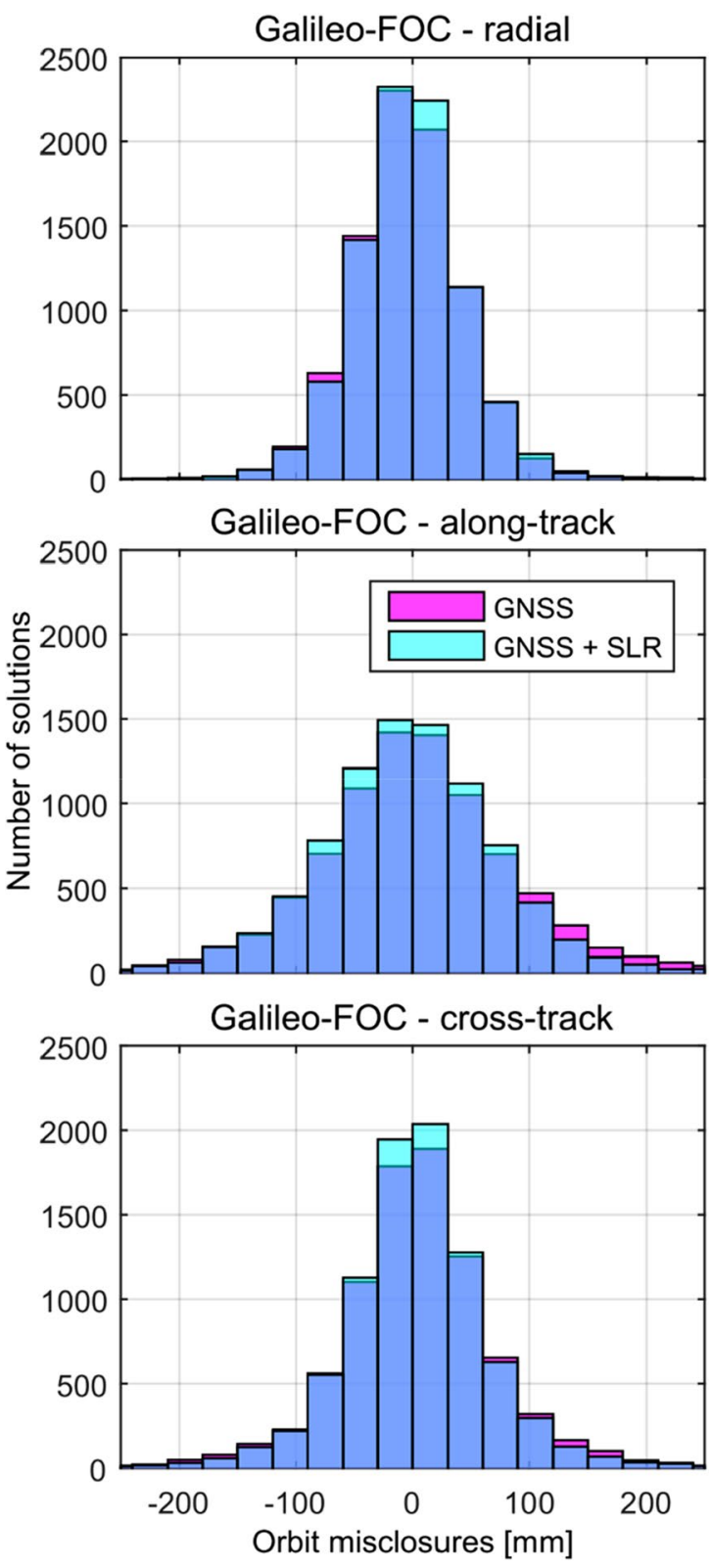

Fig. 4 Galileo-FOC orbit misclosures for the microwave solution $M 1$ (magenta) and the combined solution $W 1$ (cyan) value of the orbit misclosures becomes smaller with the increase of the SLR weight for both FOC and IOV satellites. However, the STD and mean value of misclosures is higher for solutions $W 2$ and $W 3$ in both along-track and cross-track directions. Although the formal error of the semimajor axis decreases with the strengthening of the impact of SLR observations, the orbit consistency suffers when the SLR observations have higher weights in $W 3$ compared to $W 1$, which reflects best the accuracy of the two techniques. For the solution $W 1$, in all directions, the STD of the orbit misclosures is lower than for $M 1$, which is reflected in Fig. 4 by the accumulation of more solutions around the zero value. Although in the along-track direction, the absolute mean values of the orbit misclosures are higher in $W 1$ than in $M 1$ and with a negative sign, the orbit solution is more consistent, i.e., the STD is lower for the combined solution. According to Bury et al. (2019a), the least accurately determined GNSS orbit component is the cross-track direction when based solely on SLR. However, using the combined GNSS and SLR solutions, the cross-track component, as well as the other directions, are improved by adding SLR observations to microwave-only solutions. When properly weighted, the STD of the orbit misclosures decreases from 47 to 46 , 83 to 75 , and 67 to $61 \mathrm{~mm}$ in the radial, along-track, and cross-track directions, respectively, from the $M 1$ to the $W 1$ solution.

\section{SLR residual analysis}

SLR residual analysis represents an external validation tool for microwave-derived orbits. In this study, however, we calculate both the microwave and hybrid solutions, which are based on both observation types, thus, the SLR validation is not fully independent.

Table 5 shows the statistics of SLR residuals for all the Galileo-IOV and FOC satellites. The STD of SLR residuals decreases when the SLR observations are added to the solution, i.e., from 26.6 and 29.3 to 25.0 and $26.8 \mathrm{~mm}$ in the case of $W 1$ for FOC and IOV satellites, respectively. When the impact of SLR is increased in solution $W 2$, both the offset and STD of SLR residuals further decrease for all Galileo satellites, i.e., to 24.4 and $25.5 \mathrm{~mm}$ for FOC and IOV, respectively. However, when the weight of the SLR observations is equal to GNSS (W3), the STD of SLR residuals is higher than for $W 2$. For strategy $W 3$, the STD of the SLR residuals increases by $8 \%$ compared to $W 2$. The decreasing offset for the combined solution may suggest that the solutions based on the two techniques become dominated by SLR (Fig. 5). Although the offset for the Galileo-FOC diminishes to almost zero, the solution $W 3$ seems to be incorrectly dominated by SLR observations. 
Table 4 Orbit misclosures for Galileo-FOC and Galileo-IOV for microwave-only $(M 1)$ and all combined strategies (W1-3). All values are given in $\mathrm{mm}$

\begin{tabular}{|c|c|c|c|c|c|c|}
\hline & \multicolumn{2}{|l|}{ Radial } & \multicolumn{2}{|c|}{ Along track } & \multicolumn{2}{|c|}{ Cross-track } \\
\hline & Mean & $\overline{\text { STD }}$ & Mean & $\overline{\text { STD }}$ & $\overline{\text { Mean }}$ & STD \\
\hline \multicolumn{7}{|l|}{ FOC } \\
\hline$M 1$ & -4.8 & 47.3 & 2.3 & 82.7 & 3.5 & 66.6 \\
\hline$W 1$ & -3.9 & 45.7 & -3.6 & 74.8 & 3.0 & 61.2 \\
\hline$W 2$ & -2.5 & 49.0 & -7.9 & 83.4 & 3.3 & 66.1 \\
\hline$W 3$ & -0.1 & 65.2 & -23.7 & 88.4 & 4.4 & 71.5 \\
\hline \multicolumn{7}{|l|}{ IOV } \\
\hline$M 1$ & -13.6 & 58.0 & 3.5 & 98.6 & -1.6 & 76.2 \\
\hline$W 1$ & -11.2 & 56.7 & -0.4 & 87.7 & -0.5 & 69.6 \\
\hline$W 2$ & -8.1 & 59.2 & 5.6 & 98.2 & -0.4 & 76.5 \\
\hline$W 3$ & -3.2 & 74.2 & -1.5 & 101.8 & 6.3 & 82.3 \\
\hline
\end{tabular}

Table 5 SLR residual statistics for FOC and IOV satellites. All values are given in $\mathrm{mm}$

\begin{tabular}{lrrrr}
\hline & \multicolumn{1}{l}{$M 1$} & \multicolumn{1}{l}{$W 1$} & \multicolumn{1}{l}{$W 2$} & \multicolumn{1}{l}{$W 3$} \\
\hline FOC & & & & \\
Mean & 11.0 & 9.1 & 5.3 & 0.0 \\
STD & 26.6 & 25.0 & 24.4 & 26.5 \\
IOV & & & & \\
Mean & -14.7 & -12.5 & -8.5 & -4.2 \\
STD & 29.3 & 26.8 & 25.5 & 27.1 \\
STD for $|\beta|>60^{\circ}$ & 36.3 & 30.8 & 29.6 & 30.1 \\
\hline
\end{tabular}

The Galileo-IOV orbits suffer from systematic effects when $|\beta|$ is higher than $60^{\circ}$. This spurious effect in Galileo IOV orbits was also detected in the experimental microwavebased IGS combined orbits (Sośnica et al. 2020). The application of the SLR minimizes these $\beta$-dependent effects, as the SLR observations directly control the radial direction of the orbit. As a result, the STD of residuals for the IOV satellites while $|\beta|>60^{\circ}$ decreases from 36.3 to $29.6 \mathrm{~mm}$ for the solutions $M 1$ and $W 2$. For high $\beta$ angles, the orbital direction $B$ of the ECOM model coincides with the radial direction that is measured directly by SLR, which means that the effect should also be visible in the $B_{0}$ parameter.

Figure 6 illustrates the SLR residuals as a function of the sun-satellite-earth geometry, i.e., the $\beta$ angle and the argument of the latitude of the satellite with respect to the argument of the latitude of the Sun $(\Delta u)$. Considering SLR observations in POD diminishes the STD of the SLR residuals by approximately 8 and 13\% for the FOC and IOV, respectively, when compared to the solution $M 1$. The positive impact of the SLR residuals for the IOV satellites for $|\beta|>60^{\circ}$ is visible in the whole range of $\Delta u$.

Figure 7 illustrates the percentage share of SLR residuals divided into $1-\mathrm{cm}$ intervals. When adding the SLR observations, the number of the SLR residuals smaller than 1-cm increases for strategies $W 1$ and $W 2$. The highest

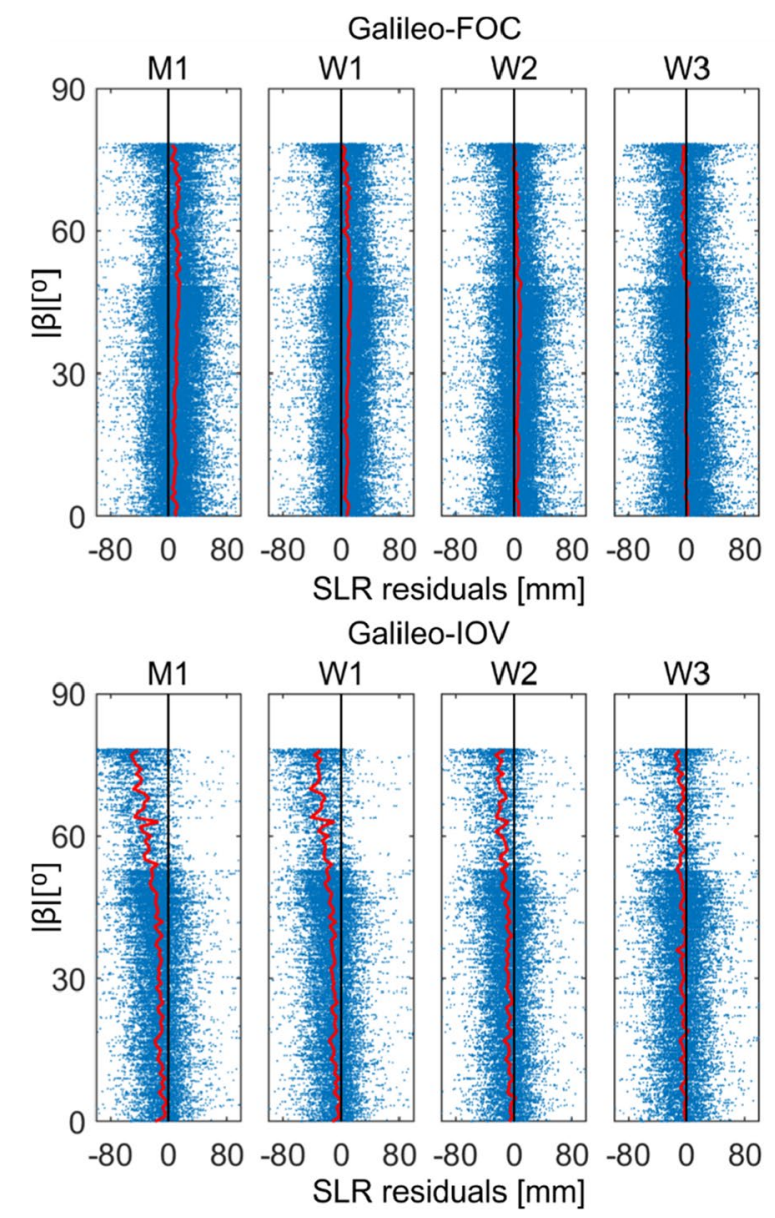

Fig. 5 SLR residuals as a function of the $|\beta|$ angle for all solutions for the Galileo-IOV (top) and Galileo-FOC (bottom). Faint dots denote single residuals and the red line denotes the median value (per bin of $\left.1^{\circ}\right)$

percentage share of the residuals below $2 \mathrm{~cm}$ for the FOC satellites is obtained for solution $W 2$ and comprises $71.7 \%$ of all observations. For solutions $M 1, W 1$, and $W 3$, the SLR residuals below $2 \mathrm{~cm}$ comprise 60.6. 66.0, and 68.5\%, 

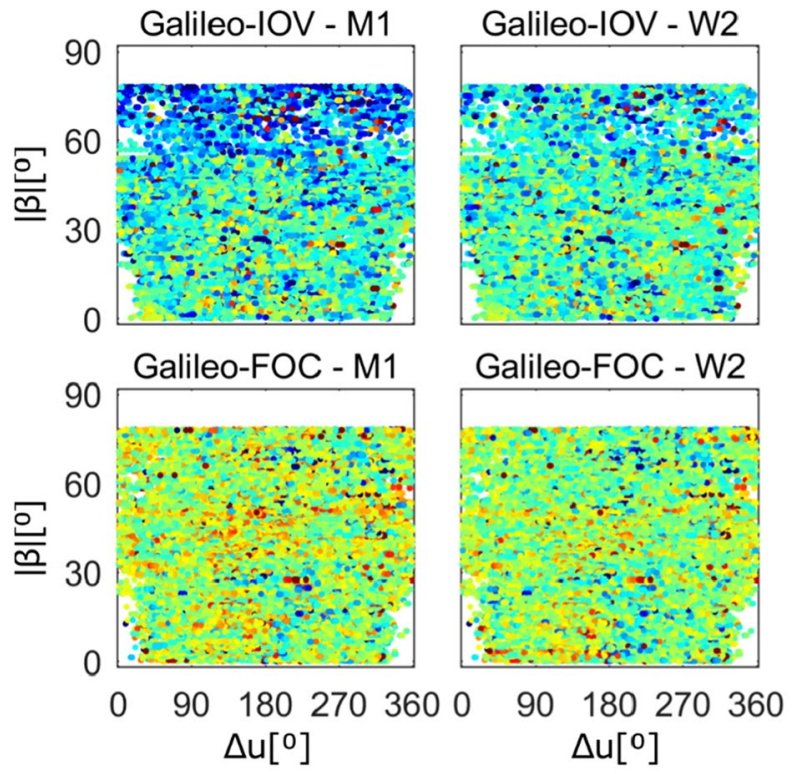

$\begin{array}{lllllllll}-80 & -60 & -40 & -20 & 0 & 20 & 40 & 60 & 80\end{array}$

Fig. 6 SLR residuals as a function of $|\beta|$ and $\Delta \mathrm{u}$ for Galileo-IOV (top) and Galileo-FOC (bottom) for the microwave ( $M 1-$ left) and combined solutions $(W 2-$ right $)$. All values in $\mathrm{mm}$

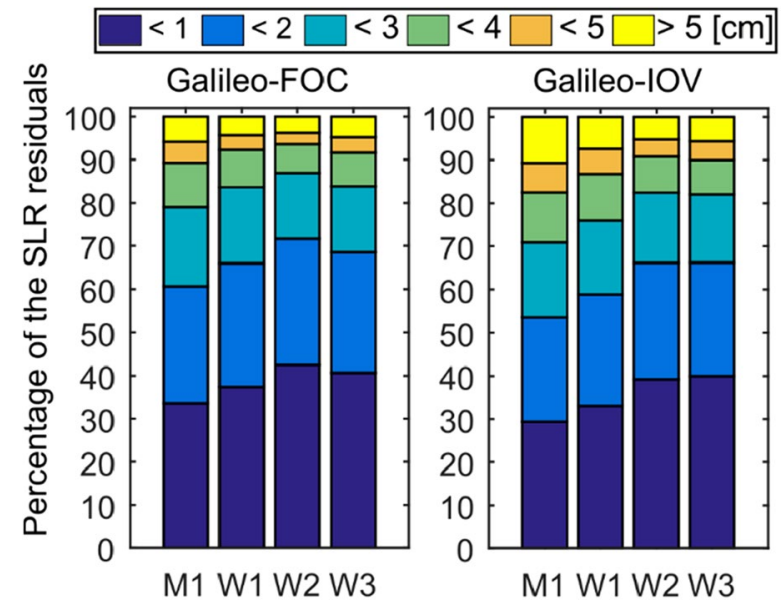

Fig. 7 Percentage share of the SLR residuals characterized by the accuracy better than $1,2,3,4$, and $5 \mathrm{~cm}$, and worse than $5 \mathrm{~cm}$

respectively for FOC satellites. Moreover, the lowest number of the SLR residuals exceeding $5 \mathrm{~cm}$ is also obtained for strategy $W 2$, i.e., $3.8 \%$. For IOV satellites, the strategy $W 3$ might look more consistent than the solution $W 2$; however, the number of SLR residuals exceeding $5 \mathrm{~cm}$ for FOC satellites is higher for $W 3$ than for $W 2$. Solution $W 2$ seems to provide the most reasonable combination of SLR and GNSS observations; therefore, the further analyses will concentrate on $W 2$.

\section{Impact of the SLR observations on empirical orbit parameters}

The empirical orbit parameters typically reveal the deficiencies in the applied force models. In the previous section, we found that SLR substantially improves the Galileo-IOV orbit quality for $|\beta|>60^{\circ}$ when the $B_{0}$ term coincides with the radial component measured directly by the SLR technique.

Figure 8 shows differences between estimated empirical parameter $B_{0}$ from strategies $M 1$ and $W 2$ for GalileoIOV E19 and Galileo-FOC E08. The differences of other empirical orbit parameters indicate a non-systematic flat course with the median of $0.001-0.003 \mathrm{~nm} / \mathrm{s}^{2}$, thus they are not shown here. Although the SLR residuals do not directly indicate a systematic effect for high $|\beta|$ angles for the FOC satellites, the differences between $B_{0}$ parameters, estimated using the microwave (M1) and combined (W2) solutions, show a dependency on $|\beta|$. The overall median difference of $B_{0}$ for the Galileo-FOC E08 when $|\beta|>60^{\circ}$ is at the level of $0.16 \mathrm{~nm} / \mathrm{s}^{2}$, which corresponds to a reduction at the level of $25 \%$ toward zero value. The maximum difference of $B_{0}$ is $1.86 \mathrm{~nm} / \mathrm{s}^{2}$ for FOC. The majority of $B_{0}$ differences for Galileo-IOV E19 are negative with the maximum value of $-2.40 \mathrm{~nm} / \mathrm{s}^{2}$ and the median improvement is at the level of $0.50 \mathrm{~nm} / \mathrm{s}^{2}$, which corresponds to the reduction of the estimated values of $B_{0}$ by $23 \%$ toward zero accelerations.

To conclude, for both IOV and FOC satellites, the absolute values of $B_{0}$ estimates in the combined solutions are lower, i.e., closer to 0 . That is especially visible for high $\beta$ angles when the direction $B$ is close to being aligned with the orbit radial direction and would fully correspond to it if $|\beta|$ reaches $90^{\circ}$. The radial direction is directly measured by SLR. Therefore, SLR stabilizes the orbit for the maximum values of the $\beta$ angle, resulting in lower estimates for the $B_{0}$ parameter.
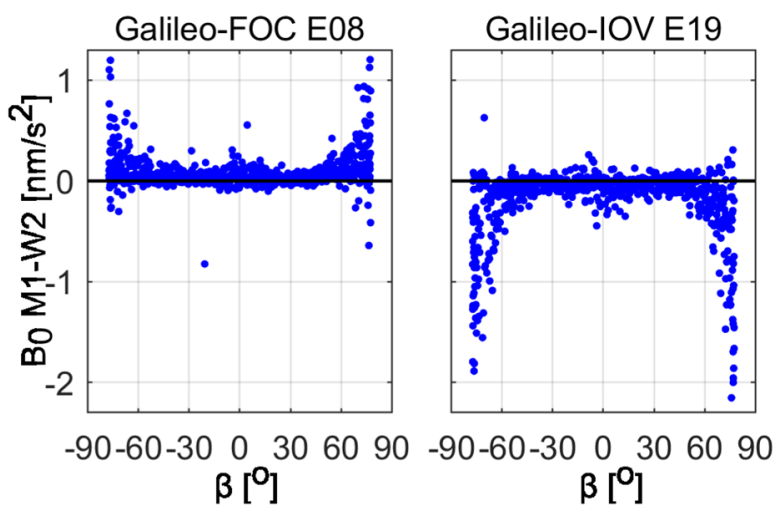

Fig. 8 Differences between empirical parameter $B_{0}$ estimated in solutions $M 1$ and $W 2$ for the Galileo-FOC E08 (left) and Galileo-IOV E19 (right) as a function of $\beta$ angle 


\section{Impact of the SLR observations on the satellite positions}

Let us now check the impact of the combined solution on the satellite positions. Although the differences between satellite positions neither specify the absolute orbit accuracy nor indicate a more suitable orbit determination strategy, they may show differences induced by, in this case, the addition of the SLR observation to GNSS satellites in the processing.

We compute the differences between satellite positions calculated from the microwave (M1) and combined (W2) solutions every $15 \mathrm{~min}$. Figure 9 illustrates the differences for Galileo-FOC E08 and Galileo-IOV E19 as a function of the $\beta$ angle. This analysis corresponds to the results from Fig. 8, i.e., the differences in the satellite positions in the radial direction are consistent with the differences between the estimated parameters $B_{0}$. For both GalileoFOC and IOV, the differences in the radial direction have the same sign as the differences between $B_{0}$ estimates. For the Galileo-FOC, the differences reach up to $3.9 \mathrm{~cm}$ with the STD of $1.3 \mathrm{~cm}$ for $|\beta|>60^{\circ}$. For the Galileo-IOV E19, for which the differences are negative, the highest absolute impact from the addition of SLR is at the level of $5.6 \mathrm{~cm}$. Differences are also visible for the eclipsing period for the along-track component, i.e., for $|\beta|<12.6^{\circ}$, they fall between -3.4 and $2.2 \mathrm{~cm}$ for E08 and -4.3 and $2.1 \mathrm{~cm}$ for E19. The cross-track component does not show a prominent pattern, as it is not determined by SLR as reliably as the two remaining components (Bury et al. 2019a). The cross-track component is well defined by a dense GNSS network, and hence, SLR has a very moderate impact on the orbit position in this direction, even when employing the highest weights.
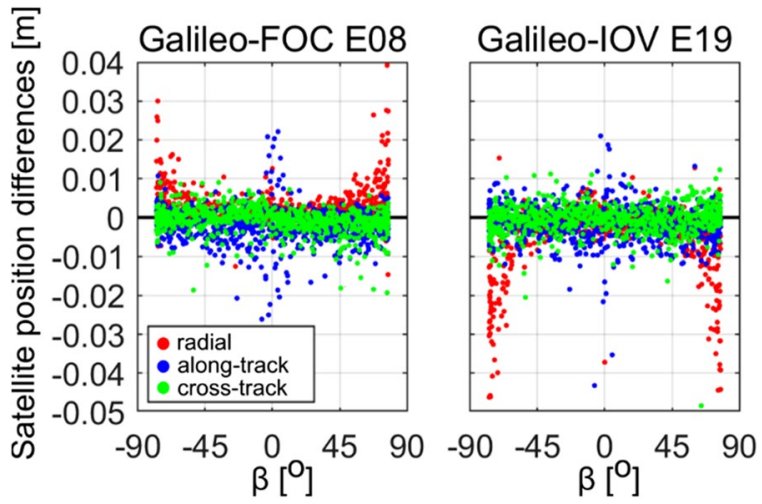

Fig. 9 Differences between satellite positions determined using the microwave $(M 1)$ and combined $(W 2)$ solutions decomposed into the radial, along-track, and cross-track directions for Galileo-FOC E08 (left) and Galileo-IOV E19 (right)

\section{Impact of the combined solution on the Length-of-Day parameter}

The orbit solution cannot be considered stable unless the remaining estimated global geodetic parameters are determined reliably. The quality of the estimated ERPs is crucial for POD as they comprise the transformation parameters linking the celestial reference frame with the TRF. The rate of UT1-UTC is sensitive to systematic errors included in satellite orbits, thus can be used as another orbit validation tool. The quality of ERPs from multiGNSS solutions is studied in Zajdel et al. (2020); hence in this study, we focus on the accumulated LoD values as this parameter depends on Kepler orbit parameters, that is, $\frac{d}{d t}(\mathrm{UT} 1-\mathrm{UTC})=-\mathrm{LoD}=-\frac{\dot{\boldsymbol{\Omega}}+\cos (i) \cdot \dot{u}}{k}$ (Rothacher et al. 1999, 2001; Ray 2009), where $\Omega$ is the right ascension of the ascending node, $i$ is the inclination, $u$ is the argument of latitude of the satellite, and $k$ is the ratio of the universal time to sidereal time. The ERPs are estimated with $24 \mathrm{~h}$ resolution as two offsets at the beginning and the end of each day. The first value of UT1-UTC for the midnight epoch is fixed to the a priori value from IERS-C04-14 provided by Very Long Baseline Interferometry (VLBI). LoD is then estimated as the change of UT1-UTC over one day. Figure 10 illustrates the accumulated LoD for all strategies. We check how quickly LoD would drift away from the reference value. The solution which is based solely on the GNSS data indicates the highest drift at the level of $-4.8 \mathrm{~ms} /$ year. When adding SLR observations, the drift diminishes. However, when the contribution of SLR has the lowest weight in $W 1$,

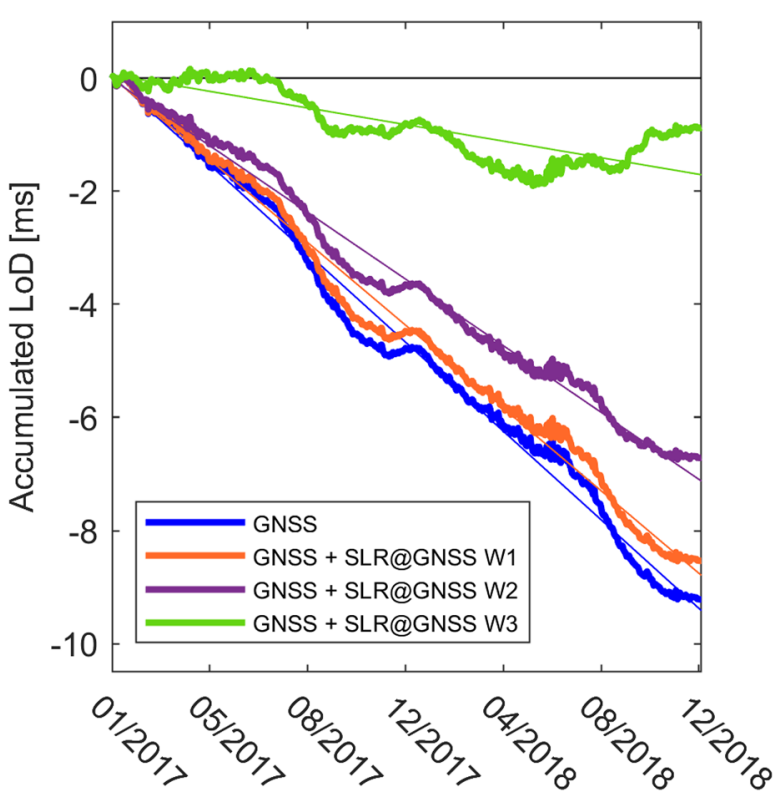

Fig. 10 Accumulated LoD values with respect to the IERS C04 for all the test cases with fitted linear regression function 
the drift is at the level of $-4.5 \mathrm{~ms} /$ year. On the other hand, when the SLR is treated equally with the GNSS data in W3, the drift diminishes to the level of -0.9 ms/year. However, according to all the analyses, the strategy $W 2$ provides the best results in terms of the orbit quality. The drift of LoD for $W 2$ is at the level of $-3.6 \mathrm{~ms} /$ year which is better by $20 \%$ when compared to the microwave solution.

\section{Conclusions}

All the Galileo satellites are equipped with LRAs for laser ranging. Thanks to observations provided by the ILRS stations, it is possible to conduct the combined SLR and GNSS orbit determination with an appropriate weighting between the two techniques. In this study, we determined Galileo orbits using combined GNSS and SLR observations and checked the impact of the SLR technique on the Galileo POD by testing different weighting strategies.

We found that the higher the weight of the SLR observations, the greater the reduction of the formal error of the semimajor axis that equals up to $62 \%$ for the solution $W 3$ when adding 50 SLR observations. We also found the reduction of the dependency of the formal error of the semimajor axis on the Sun elevation above the orbital plane. The largest improvement is for satellites with the highest $\beta$ angles when the Sun is almost perpendicular to the orbital plane, and the lowest $\beta$ angles during the eclipsing periods. However, the orbit misclosure statistics for the combined solution for strategy W3 with equal weights is worse than for the GNSSonly solution and for strategies $W 1$ and $W 2$. For strategy $W 3$ the 3D STD is $131 \mathrm{~mm}$ for FOC while it is at a level of 116,106 , and $117 \mathrm{~mm}$ for $M 1, W 1$ and $W 2$, respectively. For $W 3$, the STD of SLR residuals is highest from all combined solutions, i.e., $26.5 \mathrm{~mm}$ for FOC satellites, despite the mean offsets equal to zero, which suggests that this strategy is dominated by the SLR technique. The lowest STD of SLR residuals was obtained for solution $W 2$, i.e., $24.4 \mathrm{~mm}$ as compared to $26.6 \mathrm{~mm}$ for the GNSS-only solution. Moreover, for the strategy $W 2$, we noticed significant mitigation of the systematic effects for the Galileo-IOV satellites for $|\beta|>60^{\circ}$, i.e., the STD of SLR residuals for Galileo-IOV for high $|\beta|$ is at a level of 30.8 and $29.6 \mathrm{~mm}$ for $W 1$ and $W 2$, respectively as compared to $36.3 \mathrm{~mm}$ for $M 1$.

The differences between the satellite positions calculated using solutions $M 1$ and $W 2$ indicate that the highest differences occur for the radial component, which is directly measured by SLR. The largest differences are at the level of $56 \mathrm{~mm}$ for the Galileo-IOV E19 for $|\beta|>60^{\circ}$. A similar dependency was found for the differences between the estimated empirical orbit parameter $B_{0}$ from solution $M 1$ and $W 2$. For both IOV and FOC satellites, the estimated $B_{0}$ parameter is lower for the combined solution when $|\beta|>60^{\circ}$ which indicates that the SLR observations improve the Galileo orbits for high $|\beta|$-angle periods. Additionally, the drift of the accumulated LoD parameter is diminished by $20 \%$ for the solution W2 when compared to the solution $M 1$.

The quality of the combined solution is conditioned by the limitation factors affecting GNSS and SLR techniques. Concerning the GNSS technique, for Galileo, we use phase center offsets (PCO) calculated by Steigenberger et al. (2016) in the frame of Multi-GNSS Experiment (MGEX) as these values are consistent with ITRF2014 and IGS14 scales. The Galileo chamber-calibrated values of PCO and phase center variations (PCV) from the Galileo metadata might be considered to increase the quality of the GNSS solutions. However, it also introduces an offset with respect to the ITRF2014 scale. For the SLR technique, one should analyze in detail the SLR signature effect, which can introduce a systematic effect at the level of $15 \mathrm{~mm}$ for different SLR stations (Sośnica et al. 2018) as well as the scale issues in the SLR network related to missing RBs for some stations in the ITRF2014 realization. Further inconsistencies to be solved are the result of GNSS orbit modeling deficiencies, requiring, e.g., proper modeling of thermal effects related to the variable temperature of different satellite surfaces.

To conclude, the impact of the SLR observations in the combined solution may not be very large due to the limited number of SLR data provided by thirteen stations at maximum. The small number of observations enforces the incorporation of greater weights for SLR. A significant increase of the number of SLR observations would be most profitable for the combination because it would naturally increase the influence of the SLR in the combined solution. A higher number of SLR observations would also allow for the application of more restrictive data screening criteria as well as for dividing the SLR observations into two independent sets (1) dedicated to POD and (2) employed for the solution validation.

Currently, the combined GNSS and SLR solutions using weighting schemes $W 1$ and $W 2$ provide accurate Galileo orbits with significantly diminished systematic effects for $|\beta|>60^{\circ}$ owing to the stabilization of the satellite positions by the SLR observations. More SLR observations of GNSS satellites would be beneficial for the identification of remaining inconsistencies and, eventually, for the full exploitation of the SLR-GNSS co-location in space.

Acknowledgements The IGS MGEX is acknowledged for providing multi-GNSS data. We thank the ILRS for organizing GNSS tracking campaigns. This work was funded by the National Science Centre (NCN), Poland. G. Bury is supported by the Grants UMO-2018/29/N/ST10/00289 and UMO-2018/29/B/ST10/00382. K. Sośnica, R. Zajdel, and D, Strugarek are supported by the Grant UMO-2018/29/B/ST10/00382. G. Bury acknowledges also the Polish National Agency for Academic Exchange for the PROM Programme: 
PI/PRO/2019/1/00004/U/00001. We also thank the Wroclaw Center of Networking and Supercomputing computational grant using MATLAB Software License No: 101979 (https://www.wcss.wroc.pl).

Data availability The GNSS and SLR observations used for this study can be freely downloaded from the Crustal Dynamics Data Information System ftp://cddis.nasa.gov/gnss/ and ftp://cddis.nasa.gov/slr/products. The metadata for the Galileo satellites are provided by the GSA at https ://www.gsc-europa.eu/.

Open Access This article is licensed under a Creative Commons Attribution 4.0 International License, which permits use, sharing, adaptation, distribution and reproduction in any medium or format, as long as you give appropriate credit to the original author(s) and the source, provide a link to the Creative Commons licence, and indicate if changes were made. The images or other third party material in this article are included in the article's Creative Commons licence, unless indicated otherwise in a credit line to the material. If material is not included in the article's Creative Commons licence and your intended use is not permitted by statutory regulation or exceeds the permitted use, you will need to obtain permission directly from the copyright holder. To view a copy of this licence, visit http://creativecommons.org/licenses/by/4.0/.

Open Access This article is licensed under a Creative Commons Attribution 4.0 International License, which permits use, sharing, adaptation, distribution and reproduction in any medium or format, as long as you give appropriate credit to the original author(s) and the source, provide a link to the Creative Commons licence, and indicate if changes were made. The images or other third party material in this article are included in the article's Creative Commons licence, unless indicated otherwise in a credit line to the material. If material is not included in the article's Creative Commons licence and your intended use is not permitted by statutory regulation or exceeds the permitted use, you will need to obtain permission directly from the copyright holder. To view a copy of this licence, visit http://creativecommons.org/licenses/by/4.0/.

\section{References}

Altamimi Z, Rebischung P, Métivier L, Collilieux X (2016) ITRF2014: a new release of the international terrestrial reference frame modeling nonlinear station motions: ITRF2014. J Geophys Res Solid Earth 121:6109-6131. https://doi.org/10.1002/2016JB013098

Appleby G, Rodríguez J, Altamimi Z (2016) Assessment of the accuracy of global geodetic satellite laser ranging observations and estimated impact on ITRF scale: estimation of systematic errors in LAGEOS observations 1993-2014. J Geod 90:1371-1388. https ://doi.org/10.1007/s00190-016-0929-2

Beutler G, Mervart L (2010) Methods of celestial mechanics. Vol. 1: Physical, mathematical, and numerical principles, 2. print. Springer, Berlin

Bizouard C, Lambert S, Gattano C, Becker O, Richard J-Y (2019) The IERS EOP 14C04 solution for Earth orientation parameters consistent with ITRF 2014. J Geod 93:621-633. https://doi. org/10.1007/s00190-018-1186-3

Böhm J, Werl B, Schuh H (2006) Troposphere mapping functions for gps and very long baseline interferometry from European centre for medium-range weather forecasts operational analysis data: troposphere mapping functions from ECMWF. J Geophys Res. https://doi.org/10.1029/2005JB003629

Bruni S, Rebischung P, Zerbini S, Altamimi Z, Errico M, Santi E (2018) Assessment of the possible contribution of space ties onboard GNSS satellites to the terrestrial reference frame. J Geod 92:383-399. https://doi.org/10.1007/s00190-017-1069-z
Bury G, Sośnica K, Zajdel R (2019a) Multi-GNSS orbit determination using satellite laser ranging. J Geod 93:2447-2463. https://doi. org/10.1007/s00190-018-1143-1

Bury G, Zajdel R, Sośnica K (2019b) Accounting for perturbing forces acting on Galileo using a box-wing model. GPS Solut. https://doi. org/10.1007/s10291-019-0860-0

Bury G, Sośnica K, Zajdel R, Strugarek D (2020) Toward the 1-cm Galileo orbits: challenges in modeling of perturbing forces. J Geod. https://doi.org/10.1007/s00190-020-01342-2

Dach R, Lutz S, Walser P, Fridez P (eds) (2015) Bernese GNSS Software Version 5.2. User manual, Astronomical Institute, University of Bern, Bern Open Publishing. http://doi.org/https://doi. org/10.7892/boris.72297; ISBN: 978-3-906813-05-9

Desai SD (2002) Observing the pole tide with satellite altimetry. J Geophys Res 107:3186. https://doi.org/10.1029/2001JC001224

Glaser S, Fritsche M, Sośnica K, Rodriguez-Solano CJ, Wang K, Dach R, Hugentobler U, Rothacher M, Dietrich R (2015) A consistent combination of GNSS and SLR with minimum constraints. J Geod 89:1165-1180. https://doi.org/10.1007/s00190-015-0842-0

GSA (2016) Galileo IOV and FOC satellite metadata URL https:// www.gsc-europa.eu/support-to-developers/galileo-iov-satellitemetadata. Accessed 20/07/21

Hackel S, Steigenberger P, Hugentobler U, Uhlemann M, Montenbruck $\mathrm{O}$ (2015) Galileo orbit determination using combined GNSS and SLR observations. GPS Solut 19:15-25. https://doi.org/10.1007/ s10291-013-0361-5

Hadas T et al (2017) Impact and Implementation of higher-order ionospheric effects on precise GNSS applications: higher-order ionospheric effects in GNSS. J Geophys Res Solid Earth 122:9420 9436. https://doi.org/10.1002/2017JB014750

Hidalgo I, Mozo A, Navarro P, Piriz R, Navarro-Reyes D (2008) Use of SLR observations to improve GIOVE-B orbit and clock determination. In: Schilliak S (ed) Proceedings of 16th international workshop on laser ranging, vol 2, Space Research Centre, Polish Academy of Sciences, pp 71-84

Luceri V, Pirri M, Rodríguez J, Appleby G, Pavlis EC, Müller H (2019) Systematic errors in SLR data and their impact on the ILRS products. J Geod 93:2357-2366. https://doi.org/10.1007/s00190-019-01319-w

Lutz S, Meindl M, Steigenberger P, Beutler G, Sośnica K, Schaer S, Dach R, Arnold D, Thaller D, Jäggi A (2016) Impact of the arc length on GNSS analysis results. J Geod 90:365-378. https://doi. org/10.1007/s00190-015-0878-1

Lyard F, Lefevre F, Letellier T, Francis O (2006) Modelling the global ocean tides: modern insights from FES2004. Ocean Dyn 56:394415. https://doi.org/10.1007/s10236-006-0086-x

Mendes VB, Pavlis EC (2004) High-accuracy zenith delay prediction at optical wavelengths. Geophys Res Lett 31:L14602. https://doi. org/10.1029/2004GL020308

Pavlis EC (1995) Comparison of GPS S/C orbits determined from GPS and SLR tracking data. Adv Space Res 16:55-58. https:// doi.org/10.1016/0273-1177(95)98780-R

Pavlis NK, Holmes SA, Kenyon SC, Factor JK (2012) The development and evaluation of the Earth Gravitational Model 2008 (EGM2008): The EGM2008 earth gravitational model. J Geophys Res. https://doi.org/10.1029/2011JB008916

Pearlman MR, Noll CE, Pavlis EC, Lemoine FG, Combrinck L, Degnan JJ, Kirchner G, Schreiber U (2019) The ILRS: approaching 20 years and planning for the future. J Geod 93:2161-2180. https ://doi.org/10.1007/s00190-019-01241-1

Petit G, Luzum B (eds) (2010) IERS conventions. Verlag des Bundesamts für Kartographie und Geodäsie, Frankfurt, Germany

Ray JR (2009) A quasi-optimal, consistent approach for combination of UT1 and LOD. In: Drewes H (ed) Geodetic reference frames. Springer, Berlin, pp 239-243 
Rebischung P, Altamimi Z, Ray J, Garayt B (2016) The IGS contribution to ITRF2014. J Geod 90:611-630. https://doi.org/10.1007/ s00190-016-0897-6

Rothacher M, Beutler G, Herring TA, Weber R (1999) Estimation of nutation using the global positioning system. J Geophys Res Solid Earth 104(B3):4835-4859. https://doi.org/10.1029/1998jb900078

Rothacher M, Beutler G, Weber R, Hefty J (2001) High-frequency variations in Earth rotation from Global Positioning System data. J Geophys Res Solid Earth 106(B7):13711-13738. https://doi. org/10.1029/2000JB900393

Scherneck H-G (1991) A parametrized solid earth tide model and ocean tide loading effects for global geodetic baseline measurements. Geophys J Int 106:677-694. https://doi.org/10.1111/ j.1365-246X.1991.tb06339.x

Schönemann E, Springer TA, Otten M, Becker M, Dow J (2007) GIOVE-A precise orbit determination from microwave and satellite laser ranging data-first perspectives for the Galileo constellation and its scientific use. In: Proceedings of First Colloquium on Scientific and Fundamental Aspects of the Galileo Programme 2007, Toulouse, France. October 1-4, 2007

Senior K, Kouba J, Ray J (2010) Status and prospects for combined GPS LOD and VLBI UT1 measurements. Artif Sat 45:57-73. https://doi.org/10.2478/v10018-010-0006-7

Sośnica K, Prange L, Kaźmierski K, Bury G, Drożdżewski M, Zajdel R, Hadas T (2018) Validation of Galileo orbits using SLR with a focus on satellites launched into incorrect orbital planes. J Geod 92:131-148. https://doi.org/10.1007/s00190-017-1050-x

Sośnica K, Bury G, Zajdel R, Strugarek D, Drożdżewski M, Kazmierski K (2019) Estimating global geodetic parameters using SLR observations to Galileo, GLONASS, BeiDou, GPS, and QZSS. Earth Planets Space 71(1):20. https://doi. org/10.1186/s40623-019-1000-3

Sośnica K, Zajdel R, Bury G, Bosy J, Moore M, Masoumi S (2020) Quality assessment of experimental IGS multi-GNSS combined orbits. GPS Solut 24:54. https://doi.org/10.1007/s1029 1-020-0965-5

Springer TA, Beutler G, Rothacher M (1999) A new solar radiation pressure model for GPS satellites. GPS Solut 2:50-62. https:// doi.org/10.1007/PL00012757

Steigenberger P, Hugentobler U, Montenbruck O, Hauschild A (2011) Precise orbit determination of GIOVE-B based on the CONGO network. J Geod 85:357-365. https://doi.org/10.1007/ s00190-011-0443-5

Steigenberger P, Fritsche M, Dach R, Schmid R, Montenbruck O, Uhlemann M, Prange L (2016) Estimation of satellite antenna phase center offsets for Galileo. J Geod 90:773-785. https://doi. org/10.1007/s00190-016-0909-6

Steigenberger P, Thoelert S, Montenbruck O (2018) GNSS satellite transmit power and its impact on orbit determination. J Geod 92:609-624. https://doi.org/10.1007/s00190-017-1082-2

Strugarek D, Sośnica K, Arnold D, Jäggi A, Zajdel R, Bury G, Drożdżewski M (2019) Determination of global geodetic parameters using satellite laser ranging measurements to sentinel-3 satellites. Remote Sens 11(19):2282. https://doi.org/10.3390/ rs 11192282

Thaller D, Dach R, Seitz M, Beutler G, Mareyen M, Richter B (2011) Combination of GNSS and SLR observations using satellite co-locations. J Geod 85:257-272. https://doi.org/10.1007/s0019 $0-010-0433-\mathrm{Z}$

Thaller D, Sośnica K, Dach R, Jäggi A, Beutler G, Mareyen M, Richter B (2014) Geocenter coordinates from GNSS and combined GNSS-SLR solutions using satellite co-locations. In: Rizos C, Willis P (eds) Earth on the edge: science for a sustainable planet. Springer, Berlin, pp 129-134

Thaller D, Sośnica K, Steigenberger P, Roggenbuck O, Dach R (2015) Pre-combined GNSS-SLR Solutions: what could be the benefit for the ITRF? In: van Dam T (ed) REFAG 2014. Springer, Cham, pp 85-94

Urschl C, Beutler G, Gurtner W, Hugentobler U, Schaer S (2007) Contribution of SLR tracking data to GNSS orbit determination. Adv Space Res 39:1515-1523. https://doi.org/10.1016/j. asr.2007.01.038

Urschl C, Gurtner W, Hugentobler U, Schaer S, Beutler G (2005) Validation of GNSS orbits using SLR observations. Adv Space Res 36:412-417. https://doi.org/10.1016/j.asr.2005.03.021

Wielicki BA, Barkstrom BR, Harrison EF, Lee RB, Smith GL, Cooper JE (1996) Clouds and the earth's radiant energy system (CERES): an earth observing system experiment. Bull Am Meteorol Soc 77(5):853-868. https://doi.org/10.1175/15200477(1996)077\%3c0853:CATERE\%3e2.0.CO;2

Zajdel R, Sośnica K, Bury G (2017) A new online service for the validation of multi-GNSS orbits using SLR. Remote Sens 9:1049. https://doi.org/10.3390/rs9101049

Zajdel R, Sośnica K, Dach R, Bury G, Prange L, Jäggi A (2019a) Network effects and handling of the geocenter motion in multiGNSS processing. J Geophys Res Solid Earth 124:5970-5989. https://doi.org/10.1029/2019JB017443

Zajdel R, Sośnica K, Drożdżewski M, Bury G, Strugarek D (2019b) Impact of network constraining on the terrestrial reference frame realization based on SLR observations to LAGEOS. J Geod 93:2293-2313. https://doi.org/10.1007/s00190-019-01307-0

Zajdel R, Sośnica K, Bury G, Dach R, Prange L (2020) Systemspecific systematic errors in earth rotation parameters derived from GPS, GLONASS, and Galileo. GPS Solut 24:74. https:// doi.org/10.1007/s10291-020-00989-w

Publisher's Note Springer Nature remains neutral with regard to jurisdictional claims in published maps and institutional affiliations.

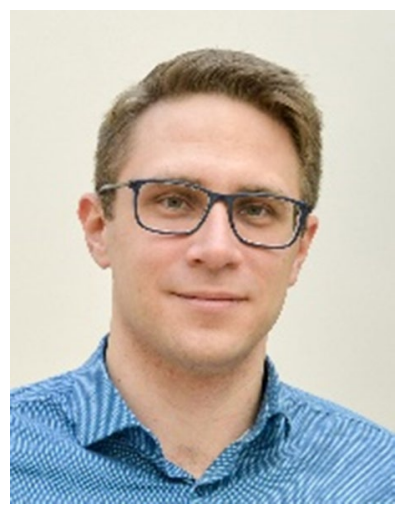

Grzegorz Bury received a Ph.D. degree in satellite geodesy from UPWr in 2020. His research interests include precise orbit determination of GNSS satellites using SLR observations and the improvement of the consistency between SLR and GNSS solutions.

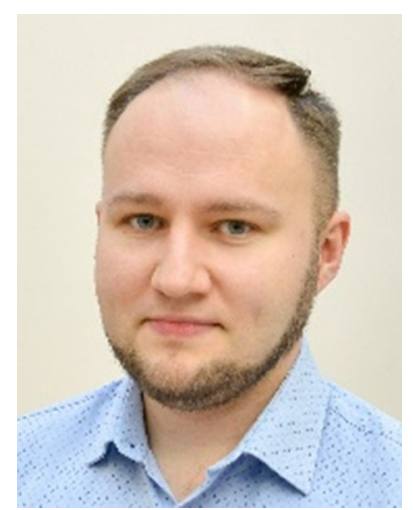

Krzysztof Sośnica received a $\mathrm{Ph} . \mathrm{D}$. degree in physics from the University of Bern, Bern, Switzerland, in 2014 and currently works as a professor and head of the Department for Satellite Geodesy at UPWr. His research interests include processing GNSS and SLR observations for deriving geodetic parameters. 

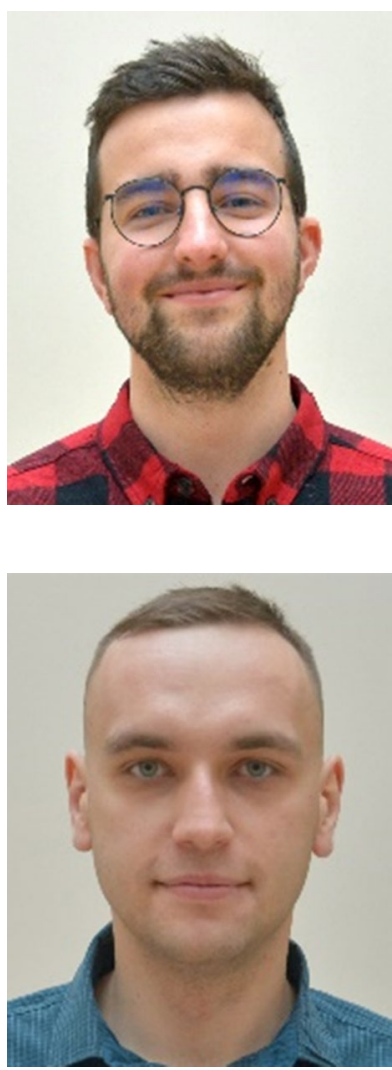

Radosław Zajdel received a master's degree from UPWr, Wrocław, Poland, in 2017, where he is currently pursuing a Ph.D. degree in space geodesy. His research interests include the determination of global geodetic parameters in multi-GNSS solutions and the analysis of SLR observations to GNSS satellites.

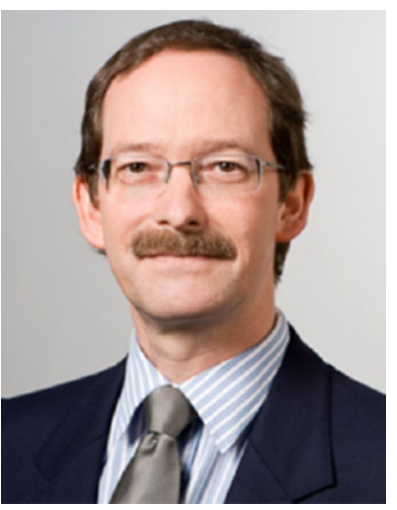

Urs Hugentobler is a professor of Technische Universität München, Germany, and head of the Research Facility Satellite Geodesy. His research activities focus on precise applications of GNSS such as positioning, precise orbit determination, reference frame realization, and time transfer.
Dariusz Strugarek received a master's degree from UPWr, Wrocław, Poland, in 2017, where he is currently pursuing a Ph.D. degree in space geodesy. His research interests include the determination of SLR station coordinates and global geodetic parameters based on SLR observations to geodetic, LEO, and GNSS satellites. 